This item was submitted to Loughborough's Research Repository by the author.

Items in Figshare are protected by copyright, with all rights reserved, unless otherwise indicated.

\title{
An investigation of string cavitation in a true-scale fuel injector flow geometry at high pressure
}

PLEASE CITE THE PUBLISHED VERSION

PUBLISHER

(C) American Institute of Physics

\section{VERSION}

VoR (Version of Record)

\section{LICENCE}

CC BY-NC-ND 4.0

\section{REPOSITORY RECORD}

Reid, Benjamin A., Graham K. Hargrave, Colin P. Garner, and Graham Wigley. 2019. "An Investigation of String Cavitation in a True-scale Fuel Injector Flow Geometry at High Pressure". figshare. https://hdl.handle.net/2134/6065. 
This item was submitted to Loughborough's Institutional Repository (https://dspace.lboro.ac.uk/) by the author and is made available under the following Creative Commons Licence conditions.

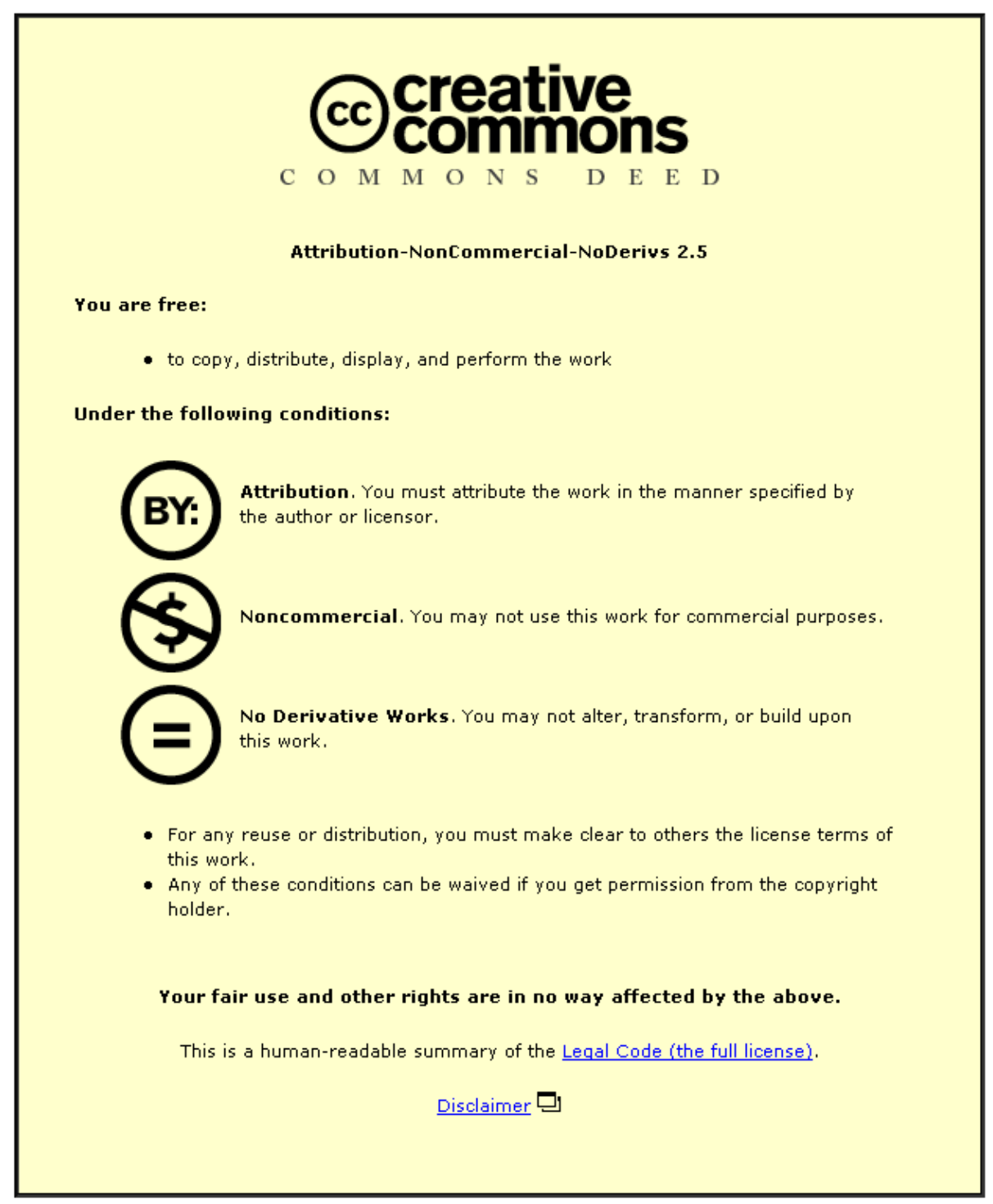

For the full text of this licence, please go to: http://creativecommons.org/licenses/by-nc-nd/2.5/ 


\title{
An investigation of string cavitation in a true-scale fuel injector flow geometry at high pressure
}

\author{
B. A. Reid, G. K. Hargrave, C. P. Garner, and G. Wigley \\ Faculty of Engineering, Loughborough University, Loughborough, \\ Leicestershire LE11 3TU, United Kingdom
}

(Received 11 November 2009; accepted 24 February 2010; published online 26 March 2010)

\begin{abstract}
String cavitation has been studied in an optical automotive size fuel injector with true-scale flow geometry at injection pressures of up to 2050 bar. The multihole nozzle geometry studied allowed observation of the hole-to-hole vortex interaction and, in particular, that of a bridging vortex in the sac region between the holes. A dependency on Reynolds number was observed in the formation of the visible, vapor filled vortex cores. Above a threshold Reynolds number, their formation and appearance during a $2 \mathrm{~ms}$ injection event was repeatable and independent of upstream pressure and cavitation number. (C) 2010 American Institute of Physics. [doi:10.1063/1.3372174]
\end{abstract}

Cavitation in nozzle flows has been widely investigated using both experimental and computational approaches. ${ }^{1}$ Experimental studies ${ }^{2,3}$ have, until now, been limited to obtaining optical flow data from scaled experimental rigs. Fluid pressures are often reduced and flow geometries increased, particularly in the case of diesel injector flows, which typically operate at pressures exceeding 1500 bar in nozzle holes less than a few hundred microns in diameter. This leaves little or no knowledge of the actual internal flow behavior at realistic operating conditions. Computer modeling ${ }^{4}$ has allowed these flow environments to be investigated beyond the scope of the experimental studies; however, suitable data to validate the simulated results have not been available.

While previous studies ${ }^{1}$ have for the most part concentrated on in-hole cavitation, typically formed in the recirculation zone at the hole inlet, recent experimental studies by Arcoumanis et al. ${ }^{5}$ revealed the presence of additional cavitation structures in the sac volume of valve covered orifice (VCO) and minisac type fuel injectors. Appearing similar to vortex cavitation, as observed in propeller flows, ${ }^{6}$ the presence of "cavitation strings" in injector flows has not been widely documented. Gavaises and Andriotis ${ }^{7}$ and Andriotis et al., ${ }^{8}$ however, showed that the dynamic nature of the nozzle-hole cavitation and sac-vortex interaction leads to hole-to-hole variations in hole flow and spray angle that were attributed to the presence of vortices in the hole entrance region. Although it remains important to quantify the potential influence of these near-hole vortices on the downstream nozzle flow, it is essential to consider the mechanisms of their formation if they are to be controlled and their influence is to be exploited.

The present work has visualized the formation of string cavitation in the near-hole region of a true-scale optical multihole fuel injector. It was designed to replicate the asymmetric hole-inlet flow characteristics of a VCO or minisac type injector, shown in Fig. 1, where the flow in the sac volume, between the conical needle tip and the injector casing, must rapidly change direction to exit through the nozzle hole. A multihole design was used to allow observation of the holeto-hole vortex interaction.
Fuel injection pressures of 2050 bar were achieved using a high pressure fuel injection test rig based on a common rail hardware setup. This allowed the behavior of the flow structures to be studied at the maximum working pressures of current common rail fuel injector systems.

A nonoptical diesel fuel injector, modified to include a large single outlet hole, delivered high pressure diesel fuel to the optical nozzle assembly that was positioned downstream of its exit. This produced realistic transient fuel injection events of $2 \mathrm{~ms}$ duration in the optical nozzle.

Injections were imaged at upstream fuel injection pressures, $\mathrm{P}_{1}$, ranging from 300 to $2050 \mathrm{bar}$ (absolute). Cavitation number $\left[\sigma=\left(\mathrm{P}_{1}-\mathrm{P}_{2}\right) / \mathrm{P}_{2}\right]$ and Reynolds number were controllable at each injection pressure by way of a nitrogenfilled pressure vessel fitted downstream of the optical nozzle assembly. This was capable of providing a nozzle back pressure, $\mathrm{P}_{2}$, ranging from 1 to $150 \mathrm{bar}$ (absolute). The optical nozzle was formed by clamping individual plates together to form the required internal flow geometry shown in Fig. 2.

For the purposes of this study, the nozzle consisted of a $1 \mathrm{~mm}$ thick steel multihole plate, containing three $300 \mu \mathrm{m}$ diameter straight holes arranged in a triangular pattern. This was positioned below a $2 \mathrm{~mm}$ thick sapphire plate, which contained a single $2 \mathrm{~mm}$ diameter optically polished hole in its center. This formed an optically accessible sac volume upstream of the nozzle-hole entrances, allowing the near hole-inlet flow regions to be imaged. Asymmetric inlet flows were achieved by positioning a steel "obstruction plate" above the sac plate. A semicircular protrusion extended $1.8 \mathrm{~mm}$ from the underside of the obstruction plate and slotted into the sac volume, positioned such that its height left a $200 \mu \mathrm{m}$ gap above two of the three nozzle holes. A "D" shaped hole, formed the opposing semicircle, which continued through the plate to create a D-shaped flow entrance to the sac volume. Fuel entered the sac volume such that the downward flow was forced through an angle of $90^{\circ}$, to then flow under the protrusion and exit through the two rearward nozzle holes.

The resulting asymmetry of the hole entrance flows, confined by the cylindrical sac wall, served to induce intense 


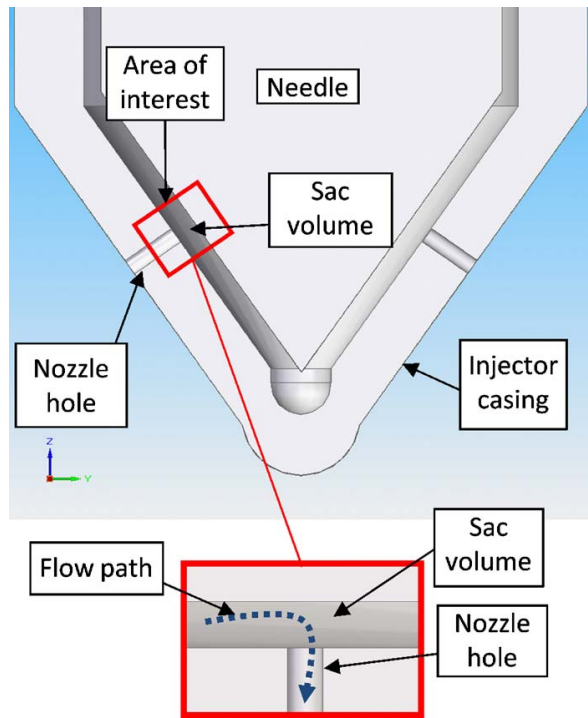

FIG. 1. (Color online) Cut-away view of a VCO type injector showing the near-hole geometry of the sac volume and the asymmetric fluid-flow path into the nozzle hole.
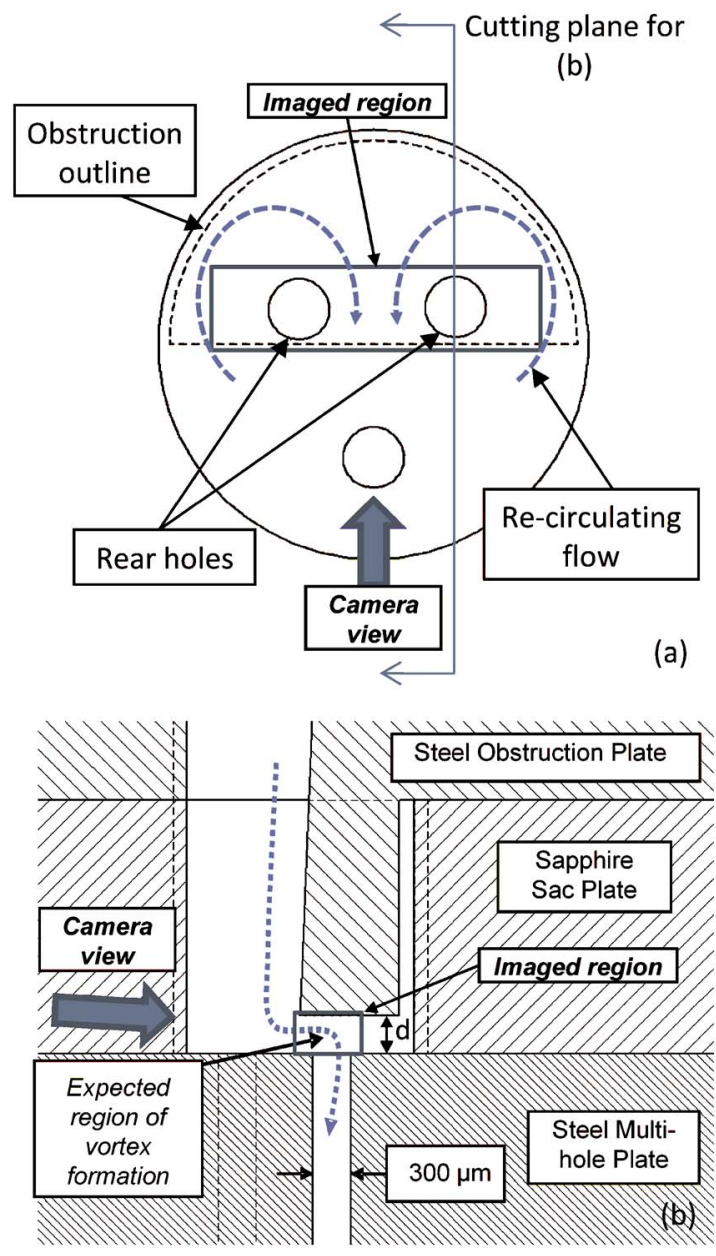

FIG. 2. (Color online) (a) Plan view of the optical nozzle showing recirculating flow around the rear holes under the obstruction and (b) section view of the optical nozzle showing nozzle construction and the flow path being forced under the obstruction before exiting through the rear holes.

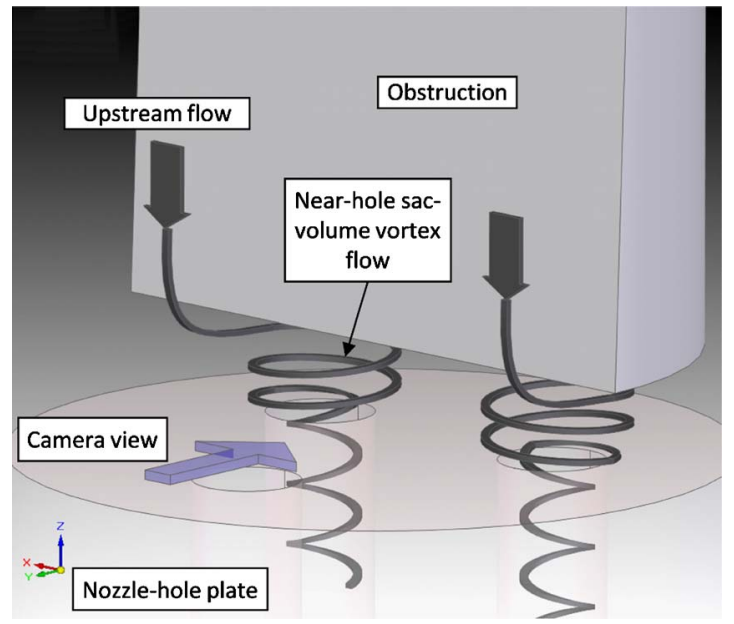

FIG. 3. (Color online) Illustration of the vortex flow generated in the nearhole region of the sac volume underneath the obstruction.

flow rotation and recirculation in the near-hole flow regions of the sac volume, as shown in Figs. 3 and 2(a), which further intensified as the outflow accelerated into the nozzle holes. This created a strong vortex in each hole, where cavitation processes led to the formation of a vapor filled core that allowed visualization of the vortex structures.

Imaging was carried out using both single-shot single lens reflex (SLR) photography and high-speed video (HSV) of a $1.5 \times 1.5 \mathrm{~mm}^{2}$ region, capturing the sac flow beneath the obstruction plate in the region of expected vortex formation. Both were synchronized with short pulse laser illumination (8-20 ns), sufficient to essentially freeze the fluid motion and capture instantaneous images of the flow structures in each frame. A fluorescein dye cell pumped by a single $8 \mathrm{~ns}$ Nd:YAG (yttrium aluminum garnet) laser pulse, and a $20 \mathrm{~ns} /$ pulse copper vapor laser beam, delivered by optical fiber illuminating a diffuser, provided back lighting for the SLR and HSV techniques, respectively.

The image shown in Fig. 4 was captured at a fuel injection pressure of 2050 bar and shows the dominant vortices that are created in the near-hole region of the sac volume by the two adjacent holes. Each hole displayed an on-axis vortex, formed by the mechanism described previously, with a vapor filled core that rises vertically out of the hole entrance and anchors to the underside of the obstruction plate. The outermost flow in these counter-rotating vortices interacted with the incoming bulk flow recirculation region under the center of the obstruction, leading to the formation of a third,

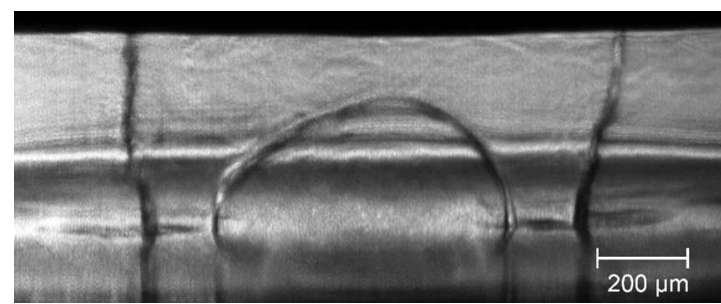

FIG. 4. Image of the vortex structures formed in the sac volume by two adjacent $300 \mu \mathrm{m}$ nozzle holes at a fuel injection pressure of 2050 bar. $\mathrm{P}_{1}$ $=2050$ bar and $\mathrm{P}_{2}=90$ bar. 


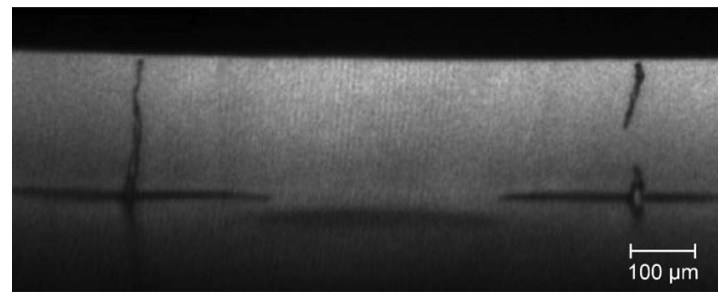

FIG. 5. Frame grab taken from fuel injection event $\mathrm{P}_{1}=400$ bar, $\mathrm{P}_{2}$ $=93$ bar, and $R e=40 \times 10^{3}$, showing suppression of the bridging vortex and signs of weakening in the vertical vortices.

lateral bridging vortex that linked the adjacent holes. This interaction is similar to vorticity bridging that was observed during the merging of two corotating wing-tip vortices presented by Chang et al. ${ }^{9}$ and suggests the transport of cavitation vapor between holes. This observation is also in keeping with the previous findings ${ }^{5,7,8}$ that observed significant holeto-hole interaction in their larger scale experimental studies.

The effect of the Reynolds number, used here to express the variation in fluid velocity, on string formation was investigated by maintaining a constant cavitation number of $\sigma$ $=3.3$ and varying $\mathrm{P}_{1}$ and $\mathrm{P}_{2}$ simultaneously. Defining the Reynolds number by the width of the flow region under the obstruction plate ( $d$ in Fig. 2), it was shown that below Re $=42 \times 10^{3}$ the appearance of the cavitation strings began to be suppressed, as can be seen in Fig. 5, to the point where they were no longer visible at $\operatorname{Re}=37 \times 10^{3}$. Above this threshold Reynolds value, changes to fuel injection pressure and back pressure had no observable influence on the appearance of the cavitation strings, displaying an independence to cavitation number and fuel injection pressure across the experimental range. Thus, it can be surmised that only the initial formation of cavitation strings is influenced by vortex intensity, which may affect the presence of a visible vortex core through vapor transport from the low pressure hole entrance regions or, by way of reducing the core pressure below the fluid vapor pressure and inducing cavitation exclusively.

It should be noted that when viewed with HSV, these string structures are highly dynamic, with no smooth frame- to-frame transitions observed at frame rates up to 42 $\times 10^{3}$ frames/s. Microscopic changes in the shape and location of the vertical strings, and the arc height of the bridging string were observed, however, the overall appearance of the structures remained consistent throughout the injection event.

In summary, cavitating flow structures have been visualized at a range of pressures up to 2050 bar in a real-scale flow geometry. This has allowed their behavior to be observed across the complete working pressure range of current common rail systems. This has furthered the understanding of the physics of high pressure nozzle flows and provided a source of comprehensive model validation data beyond the scope of previous experimental studies. The study has shown that the formation of string cavitation is initially dependent on the Reynolds number, and that once formed, changes to the fluid pressure have no influence on their appearance.

This work has been technically and financially supported by Caterpillar Inc. and the UK Technology Strategy Board under Project No. TP/3/DSM/6/I/15289.

${ }^{1}$ D. P. Schmidt and M. L. Corradini, "The internal flow of diesel injector nozzles: A review," Int. J. Engine Res. 2, 1 (2001).

${ }^{2}$ H. Chaves, M. Knapp, A. Kubitzek, F. Obermeier, and T. Schneider, "Experimental study of cavitation in the nozzle hole of diesel injectors using transparent nozzles," SAE Report No. 950290, 1995.

${ }^{3}$ H. K. Suh and C. S. Lee, "Effect of cavitation in nozzle orifice on the diesel fuel atomization characteristics," Int. J. Heat Fluid Flow 29, 1001 (2008).

${ }^{4}$ A. Mulemane, S. Subramaniyam, P. Lu, J. Han, M. Lai, and R. Poola, "Comparing cavitation in diesel injectors based on different modeling approaches," SAE Report No. 2004-01-0027, 2004.

${ }^{5}$ C. Arcoumanis, H. Flora, M. Gavaises, N. Kampanis, and R. Horrocks, "Investigation of cavitation in a vertical multi-hole injector," SAE Report No. 1999-01-0524, 1999.

${ }^{6}$ F. Pereira, F. Salvatore, and F. Di Felice, "Measurement and modeling of propeller cavitation in uniform inflow," J. Fluids Eng. 126, 671 (2004).

${ }^{7}$ M. Gavaises and A. Andriotis, "Influence of vortex flow and cavitation on near-nozzle diesel spray dispersion angle," Atomization Sprays 19, 247 (2009).

${ }^{8}$ A. Andriotis, M. Gavaises, and C. Arcoumanis, "Vortex flow and cavitation in diesel injector nozzles," J. Fluid Mech. 610, 195 (2008).

${ }^{9}$ N. A. Chang, R. Yakushiji, D. R. Dowling, and S. L. Ceccio, "Cavitation visualization of vorticity bridging during the merger of co-rotating vortices," Phys. Fluids 19, 058106 (2007). 